\title{
Corrigenda to Essays on Gödel's Reception of Leibniz, Husserl, and Brouwer
}

\author{
Mark van Atten
}

November 8, 2016

Please send further corrections to vanattenmark@gmail.com for inclusion in later versions of this list.

- p.36 line 16

AFTER Leibniz INSERT metaphysics itself. Leibniz calls

- p.37 line 5

AFTER Cantor's INSERT Cantor's set theory, then, for Leibniz would be

- p.39n.20

FOR see (2002) READ see Roth (2002)

- p.40 line $\mathrm{I} 4$

AFTER Wang INSERT reports, Gödel

- p.40 line -2 of main text

AFTER Cantor's INSERT intentions; and, although Ackermann does not point this out, this is indeed the principle that Cantor

- p.42 line -7 of main text

FOR 8 READ 58

- p.43 line -6 of main text

AFTER Gödel INSERT presented to Wang

- p.45 line 5

AFTER Wang INSERT recorded Gödel's

- p.45 line -4 of main text

FOR monad'. READ monad', 
- p.45 n.42 last line

FOR 35 READ 535

- p.46 line -4 of main text

AFTER axiom INSERT the latter collection is itself a set. It is this set the existence of which Gödel's

- p.5o line -I of main text

AFTER Gödel's INSERT assertion to Paul Benacerraf

- p.52 line 20

AFTER principle INSERT of

- p.53 line 4

AFTER according INSERT to

- p.59 line -3 of main text

INSERT in BEFORE intension

- p.I26 line -2 of main text

READ 050I9I FOR 050I20.I

- p.242 From line II onward

Even though it does not affect the content of my argument, here I committed a howler. All the lines I quote from Hill's article here are actually translations of sentences written by Husserl. Hill presents these without quotation marks or indentation, but at the end of her paragraph there is a reference to the corresponding pages in Husserliana XXIV (4II, 422, 423; and 425 must be added). I thank Dr. Hill for bringing this to my attention, and apologise for this mistaken attribution to her. The reason my argument is not affected is that the sentences Hill quotes come from a group of texts of 1908, and what I document on pages $24 \mathrm{I}-242$ is precisely how, as Husserl developed his transcendental phenomenology over the following years, he came to oppose the view that a priori ontology is not part of transcendental phenomenology. 